\title{
ARTICLE
}

\section{Teaching medical undergraduates: the psychiatrist as medical teacher ${ }^{\dagger}$}

\section{Bennett Eng}

Bennett Eng is a graduate of Dublin University and is now a higher specialist trainee (learning disability psychiatry) in the Eastern Region of the UK National Health

Service. He has a special interest in medical education and is currently completing a higher degree in medical education with Nottingham University, UK

Correspondence Dr Bennett Eng, Cambridgeshire and Peterborough NHS Foundation Trust, Block 11 Ida Darwin, Fulbourn, Cambridge CB21 5EE, UK. Email: b.eng@nhs.net

${ }^{\dagger}$ For a commentary on this article see pp. 110-113, this issue.

\begin{abstract}
SUMMARY
This article is a brief review of the teaching role of psychiatrists and is directed at psychiatrists in the UK National Health Service who teach medical undergraduates. It reviews the responsibility of delivering teaching, the delineation of teaching duties, and the teaching roles of the psychiatrist in the changing environment of medical education. Application of good principles of clinical teaching and delivery of tomorrow's doctors in line with the General Medical Council's recommendations are discussed. The article also describes a recommended core curriculum in psychiatry for undergraduates, which lays out what should be taught.
\end{abstract}

\section{DECLARATION OF INTEREST}

None.

Teaching medical students is an important part of the job for many psychiatrists in the UK's National Health Service (NHS). Teaching is delivered not only by psychiatry tutors and lecturers associated with medical schools but also by many practising psychiatrists in clinical settings. Given that recruitment of UK medical graduates into psychiatry has been in crisis for at least the past decade (Brockington 2002; Oxtoby 2008; Brown 2009), delivery of teaching by all psychiatrists should be examined. Many factors affect the career decisions of medical undergraduates, but quality of teaching received and the experience of the psychiatric clinical rotation as an undergraduate are among the most important factors that can influence the medical graduate to choose psychiatry as a career (McParland 2003).

\section{Teaching responsibilities of psychiatrists Delivering undergraduate teaching}

Teaching psychiatry to medical undergraduates is a responsibility that is shared between many psychiatrists. Some psychiatrists have job titles such as 'clinical teaching fellow' or 'lecturer', which make it clear that teaching medical undergraduates is one of their responsibilities. However, most practising psychiatrists, such as specialty registrars (CT1-ST6) and consultants, have job titles that do not explicitly indicate that they are medical teachers. The diverse range of psychiatrist job titles and employers may incorrectly imply that only some psychiatrists are responsible for teaching and others are solely involved in clinical work or research.

Psychiatrists who are in formal teaching jobs, such as lecturers, have special responsibilities for teaching and additional teaching duties. However, practising psychiatrists are not exempt from teaching duties if medical undergraduates are attached to their clinical team. Box 1 highlights the educational obligations of all doctors.

\section{Delineation of teaching responsibilities}

A wide range of psychiatrists and other professionals teach medical undergraduates. It is therefore important to ensure that there is a clear delineation of teaching responsibilities to prevent overlap and duplication, which waste time and may prevent full delivery of the undergraduate syllabus. An obvious issue is to define reasonable limits and avoid unnecessary duplication when subjects overlap (Sefton 2005). In teaching psychiatry to undergraduates, psychiatrists must recognise that there is considerable overlap with other disciplines.

BOX 1 The educational obligations of all doctors

- All doctors have a professional obligation to contribute to the education and training of other doctors, medical students and non-medical healthcare professionals on the team

- Every doctor should be prepared to oversee the work of less experienced colleagues and must make sure that students are properly supervised

- Teaching skills are not necessarily innate, but they can be learned. Those who accept special teaching responsibilities should take steps to ensure that they develop and maintain their skills

- We expect doctors to be honest and objective when assessing those they have supervised or trained. Patients may otherwise be put at risk

(General Medical Council 1999) 
Teaching on neurochemicals and neuroreceptors, for example, may already have been delivered by physiologists before the medical undergraduates begin their psychiatry rotations. Individuals teaching psychiatry should therefore check to ensure that duplicate teaching is avoided.

Lecturers, teaching fellows, tutors and other formal teaching staff affiliated to the medical school often deliver didactic lectures, help organise teaching and arrange summative examinations. Teaching in clinical settings is delivered by psychiatric clinicians on the ground. In some parts of the UK, NHS clinicians take on formal teaching duties and deliver most of the teaching.

Box 2 outlines the division of teaching responsibilities in the UK between practising clinicians and medical school staff. It highlights the teaching responsibilities that all psychiatric clinicians have and also the additional teaching responsibilities of formal teaching staff affiliated to the medical school. This delineation of teaching duties is explored further in the next section, which describes the various teaching roles of psychiatrists.

\section{The medical teacher role of psychiatrists}

Over the past two decades, the medical teacher role of doctors has been evolving alongside changes in UK medical education. There has been a greater emphasis on student autonomy in medical education, with students expected to take on more responsibility for their learning (Rowntree 1990). Integrated teaching, problem-based learning, community-based learning and core curricula with electives have been promoted (General Medical Council 1993; Walton 1993). In the context of these changes, medical teachers will have different roles to play and it is important that psychiatrists recognise their own roles in the education of medical students.

\section{BOX 2 Division of teaching responsibility}

All psychiatric clinicians

- Clinical teaching in clinical settings

- Formative assessments and feedback

- Act as role-models and mentors

Formal teaching staff (lecturers, tutors, teaching fellows)

- Lectures and small-group teaching in classrooms

- Summative assessments

- Production of teaching materials and resources

- Curriculum and course planning

- Classroom role-model
BOX 312 roles of a medical teacher

1 Lecturer in classroom setting

2 Teacher in clinical or practical class setting

3 On-the-job role-model

4 Role-model in the teaching setting

5 Mentor, personal adviser or tutor

6 Learning facilitator

7 Planning or participating in formal examinations of students

8 Curriculum planner

9 Curriculum evaluator

10 Course organiser

11 Production of study guides

12 Developing learning resource materials in the form of computer programs, videotape or print

(Harden 2000)

The good medical teacher should be more than just a lecturer or information provider (Harden 2000). Medical teachers can be involved in many different teaching activities and play various roles in the delivery of teaching. An analysis by Harden $\&$ Crosby (2000) identified 12 medical teaching roles (Box 3). Some psychiatrists will have only one role in the teaching of medical undergraduates (that of being a good role-model), but most will have several.

It is important that all psychiatrists serve as good role-models for medical undergraduates. A good role-model is a person with whom students can identify, who has qualities they would like to have and is in a position they would like to reach (Paice 2002). Good role-models are seen as important in the making of a good doctor, so psychiatrists need to reflect on the attributes that young students look for in role-models and on how they might react if they find that their seniors lack these attributes.

\section{Delivering psychiatric teaching effectively}

\section{Teaching principles}

Delivery of good clinical teaching is underpinned by sound principles and approaches. This section aims to explore a number of teaching principles and approaches that have been found to be effective by research (Irby 1994; Kernan 2000).

The following teaching principles, outlined by Irby (1994) and Kerman et al (2000), have been recommended by the American Psychiatric Association (2002) in their practical guide to teaching for psychiatric residents. 
- Actively involve students, asking many questions

- Challenge students to reason with clinical information and explain their choices Students need to have the opportunity to assimilate pertinent clinical information, arrive at a differential diagnosis and explore possible alternatives.

- Capture attention and have fun Teachers who make the material come alive help students to remember cases and teaching points. Specific ideas include role-playing (a resident can play the part of a patient with a particular symptom, complaint or mental status finding) or playing games (e.g. some services use a game-quiz format to ask students and more junior residents about specific topics).

- Connect the case to broader concepts Help students to generalise from a case or problem. For example, if a patient presents with suicidal ideation, discuss the epidemiology of and risk factors for suicide, ways of asking about suicidal thoughts and intent, and/or broaden the topic by including the relationship between depressive symptomatology, severity and suicide.

- Teach by modelling patient interactions Demonstrate interviewing techniques for students and observe students' interviews and physical examinations.

- Meet individual learners' needs Ask students 'What would you like to learn on this rotation?' and 'What kinds of issues or topics in psychiatry specifically interest you?' and address these. Be aware that different people have different learning styles.

- Support learners' autonomy and show respect Supporting autonomy means working from the student's perspective to promote their active engagement.

- Be practical, relevant, selective and realistic Think about what students (most of whom will not become psychiatrists) really need to take away from their psychiatry clerkship. It is usually wise to avoid bombarding students with esoteric bits of knowledge. Have students research specific issues related to interesting cases in which they are involved. Use gaps in team members' knowledge as opportunities for medical students to do a literature search and present a 5- to 10-minute talk.

- Provide feedback and evaluation This is an obvious, but often inadequately realised, aspect of teaching. In general, students benefit from prompt, specific and direct feedback.

A useful five-step approach to clinical teaching (Neher 1992) has also been recommended by the American Psychiatric Association:
1 Get a commitment from the student Ask the student for their interpretation of the case or data.

2 Probe for supporting evidence This allows further refinement of your appraisal of how the learner is approaching clinical problems or material. Questions might include: 'What leads you to think that?' or 'What is your differential diagnosis?'

3 Encourage discussion.

4 Reinforce what was right Praise the learner for specific actions and responses.

5 Correct a mistake or teach a general rule If there are mistakes to be corrected, choose one and focus on it. Often you can gently correct mistakes by teaching a general rule.

In the delivery of teaching, psychiatrists should consider applying these approaches and principles. UK psychiatrists must be especially mindful of the need to tailor teaching to suit the needs of medical undergraduates in the UK. These teaching approaches and principles are broadly applicable to all medical undergraduates, but common sense needs to prevail in applying them in the UK. Teaching that is not focused on the needs of the learner is less likely to be effective (National Student Forum 2009).

\section{Delivering tomorrow's doctors}

The ultimate goal of delivering teaching to medical undergraduates is to produce doctors of tomorrow who will have the appropriate knowledge, skills and attitudes to serve the public. In the delivery of teaching to medical undergraduates, psychiatrists must be mindful of the goals and recommendations of the General Medical Council (GMC).

The changes in medical education that the GMC recommends (General Medical Council 1993) include reducing the burden of factual information imposed on medical students, encouragement of learning through curiosity and use of a wide range of technological resources (Box 4).

Burdening students with large amounts of information in lectures is no longer thought to be a good way of delivering teaching to undergraduates. New learning approaches such as problem-based learning in small groups are deemed to be effective (Newman 2003) and should be used in conjunction with the appropriate support of technological resources (General Medical Council 1993).

Rather than imparting knowledge directly to medical students, psychiatrists should encourage self-learning and provide support and guidance to help medical undergraduates achieve their learning objectives. 
B0X 4 Selected GMC recommendations for delivering medical teaching

- The burden of factual information imposed on students in undergraduate medical curricula should be substantially reduced

- Learning through curiosity, the exploration of knowledge and the critical evaluation of evidence should be promoted and should ensure a capacity for self-education

- Learning systems should be informed by modern educational theory and should draw on the wide range of technological resources available

(General Medical Council 1993)

Encouraging students to adopt a deep learning style where they learn because they believe that the learning is relevant and useful can assist the learning process (Oxford Centre for Staff Development 1992). Surface learning that is motivated solely by a desire to complete a course should be discouraged (Entwistle 1992). In this regard, the onus is on the psychiatrist to motivate students and demonstrate to them the relevance of psychiatry to their future clinical practice.

In shaping the doctors of the future, psychiatrists must not only take into account new methods of teaching delivery. They must also be mindful of the competencies that medical undergraduates must attain to enable them to be competent doctors. These competencies or expected outcomes that medical undergraduates must attain before graduation have been set out by the GMC in the latest revision of Tomorrow's Doctors (General Medical Council 2009) and are laid out in Box 5.

These competencies or expected outcomes raise the question of what psychiatrists should teach medical undergraduates to ensure that they will graduate with the appropriate knowledge, skills and attitudes.

\section{The undergraduate psychiatry core curriculum}

The undergraduate psychiatry curriculum lays out the competencies or expected outcomes for medical undergraduates in psychiatry. Shaping a comprehensive undergraduate psychiatry curriculum that is fit for purpose can be quite a challenge and the Royal College of Psychiatrists has provided guidance on this matter. The College's Scoping Group on Undergraduate Education in Psychiatry (Royal College of Psychiatrists 2009) has, through consultation, developed a core curriculum for undergraduates that can be used by medical schools. This core curriculum is not compulsory but it is already being used in various medical schools, including Warwick Medical School and the School of Medicine at the University of Leeds. It provides good guidance on what should be taught to medical undergraduates and lays out clearly the knowledge, skills and attitudes that medical graduates should have. A summary of the key learning objectives or outcomes in this core curriculum is laid out in Box 6.

\section{Conclusions}

Teaching medical undergraduates is an important duty for psychiatrists, who must constantly reflect on the quality of the teaching they are delivering. Poor teaching is not only liable to produce poor doctors but is also likely to put medical graduates off a career in psychiatry (McParland 2003). Psychiatrists have an obligation to develop, improve and maintain their teaching skills to ensure high-quality teaching. Psychiatrists with special responsibilities for teaching might consider pursuing a higher degree in medical education, which can help to enhance their understanding of medical teaching (Dinniss 2007).

\section{BOX 5 Tomorrow's doctors: outcomes for graduates}

Outcomes 1: The doctor as a scholar and a scientist

- The graduate will be able to apply to medical practice the biomedical scientific principles, method and knowledge relating to: anatomy, biochemistry, cell biology, genetics, immunology, microbiology, molecular biology, nutrition, pathology, pharmacology and physiology

- Apply psychological principles, method and knowledge to medical practice

- Apply social science principles, method and knowledge to medical practice

- Apply to medical practice the principles, method and knowledge of population health and the improvement of health and healthcare

- Apply scientific method and approaches to medical research

Outcomes 2: The doctor as a practitioner

- The graduate will be able to carry out a consultation with a patient

- Diagnose and manage clinical presentations

- Communicate effectively with patients and colleagues in a medical context

- Provide immediate care in medical emergencies

- Prescribe drugs safely, effectively and economically

- Carry out practical procedures safely and effectively

- Use information effectively in a medical context

Outcomes 3: The doctor as a professional

- The graduate will be able to behave according to ethical and legal principles

- Reflect, learn and teach others

- Learn and work effectively within a multidisciplinary team

- Protect patients and improve care

(General Medical Council 2009) 
BOX 6 Summary of the key learning outcomes of the Royal College of Psychiatrists' core curriculum for medical undergraduates

\section{Knowledge}

- Prevalence and clinical presentation of common psychiatric conditions

- Biological, psychological and sociocultural factors that may predispose to, precipitate or maintain psychiatric illness

- Common psychological and physical treatments for psychiatric conditions indications, method of action, unwanted effects

- Doctor's duties and the patient's rights under mental health and mental capacity legislation

- Psychiatric emergencies, risk assessment and management of behavioural disturbance

- Classification of psychiatric disorders (ICD-10; World Health Organization 1992)

- Range of services and professionals involved in the care of people with mental illness and when psychiatrists should intervene

Areas of which knowledge is essential

- Anxiety and mood disorders, psychosis, schizophrenia, substance misuse, delirium, dementia, somatoform disorder, reaction to stress including post-traumatic stress disorder, eating disorder, personality disorder, organic brain disease, self-harm, intellectual disability, psychopharmacology: neurotransmitters, neurochemicals, recreational psychoactive drugs, commonly used psychotropic medications

\section{Skills}

- History-taking, assessment of mental state (including cognitive assessment) case write-up, presentation and discussion of a case

- Empathic screening for common mental health problems
- Evaluation of patients with abnormal fears/anxieties, pathological mood states and challenging or unusual behaviours

- Recognition of the differences between mental health problems and the range of normal responses to stress and life events

- Evaluation of information about family relationships and information from other sources

- Evaluation of the impact of psychiatric illness on a patient and those around them, including risk assessment

- Appraisal and application of information and evidence gained from literature

- Discussion with patients and relatives on the nature of the illness, management options and prognosis

Attitudes

- Use an empathic interviewing style

- Recognise the importance of the development of a therapeutic relationship with patients, including the need for their active involvement

- Demonstrate sensitivity to the concerns about the stigmatisation of psychiatric illness

- Recognise the importance of multidisciplinary teamwork

- Demonstrate awareness of capacity, consent and confidentiality issues

- Reflect on attitudes to mental health problems and how these influence their approach to patients

- Reflect on how working in mental health settings may affect their health and that of colleagues

(Summarised from Royal College of Psychiatrists 2009)

\section{References}

American Psychiatric Association (2002) Psychiatric Residents as Teachers. A Practical Guide. Committee on Graduate Education.

Brockington IF, Mumford DB (2002) Recruitment into psychiatry. British Journal of Psychiatry 180: 307-12.

Brown N, Vassilas CA, Oakley C (2009) Recruiting psychiatrists. A Sisyphean task? Psychiatric Bulletin 33: 390-2.

Dinniss S, Bowers R, Christopher A (2007) Teaching psychiatrists to teach. Qualifications in clinical education for psychiatrists. Psychiatric Bulletin 31: 107-9.

Entwistle NJ, Thompson S, Tait H (1992) Guidelines for Promoting Effective Learning in Higher Education. University of Edinburgh Centre for Research on Learning and Instruction.

General Medical Council (1993) Tomorrow's Doctors. GMC.

General Medical Council (1999) The Doctor as Teacher (archived policy document). GMC (http://www.gmc-uk.org/education/postgraduate/ doctor_as teacher.asp).

General Medical Council (2009) Tomorrow's Doctors. GMC (http://www. gmc-uk.org/education/undergraduate/tomorrows_doctors_2009.asp).

Harden RM, Crosby J (2000) The good teacher is more than a lecturer. The twelve roles of the teacher. Medical Teacher 22: 334-47.

Irby DM (1994) What clinical teachers in medicine need to know. Academic Medicine 69: 333-42.

Kernan WN, Lee MY, Stone SL (2000) Effective teaching for preceptors of ambulatory care. A survey of medical students. American Journal of Medicine 108: 499-502.

MCO answers

1 c 2 e $3 d \quad 4$ a $5 d$
McParland M, Noble LM, Livingston G, et al (2003) The effect of a psychiatric attachment on students' attitudes to and intention to pursue psychiatry as a career. Medical Education 37: 447-54.
National Student Forum (2009) Annual Report 2009. National Student Forum (http://www.nationalstudentforum.com/wordpress/wp-content/ uploads/2009/10/NSF_annual_report_2009.pdf).

Neher JO, Gordon KC, Meyer B, et al (1992) A five-step "microskills" model of clinical teaching. Journal of the American Board of Family Practice 5: 419-24.

Newman M (2003) A Pilot Systematic Review and Meta-analysis on the Effectiveness of Problem Based Learning. Learning and Teaching Support Network (http://www.medev.ac.uk/static/uploads/resources/pbl report. pdf).

Oxford Centre for Staff Development (1992) The Council for National Academic Awards Improving Student Learning Project. Oxford Centre for Staff Development.

Oxtoby K (2008) Psychiatry in crisis. BMJ Classified supplement: 27 August.

Paice E, Heard S, Moss F (2002) How important are role models in making good doctors? BMJ 325: 707-10.

Rowntree D (1990) Teaching through Self-Instruction. How to Develop Open Learning Materials. Kogan Page.

Royal College of Psychiatrists (2009) Report of the Royal College of Psychiatrists' Scoping Group on Undergraduate Education in Psychiatry. RCPsych.

Sefton AJ (2005) Charting a global future for education in physiology. Advances in Physiology Education 29: 189-93.

Walton HJ (1993) Proceedings of the World Summit on Medical Education. Medical Education 28 (suppl 1): 140-9.

World Health Organization (1992) The ICD-10 Classification of Diseases, Clinical Descriptions and Diagnostic Guidelines. World Health Organization 
MCQs

Select the single best option for each question stem

1 Changes in medical education over the past two decades include:

a less student autonomy

b less integrated teaching

c greater use of problem-based learning

$d$ introduction of core curricula without electives

e less community-based learning.

2 Educational obligations of psychiatrists do not include:

a being honest when assessing their students

b training medical students

c training non-medical healthcare professionals on their teams d developing and maintaining their teaching skills

e being subjective in assessing students.

3 It is not a role of a medical teacher to be a:

a learning facilitator

b curriculum planner

c curriculum evaluator

d hospital financial controller

e mentor.

4 The General Medical Council recommends that:

a the burden of factual information on students should be decreased

b learning by rote should be encouraged

c capacity for self-education should be discouraged d teaching should not be underpinned by modern educational theory

e critical evaluation of evidence should not be encouraged.

5 Teaching should be effectively delivered by:

a not allowing learners' autonomy in their learning

b passively involving students

c not challenging students to reason with clinical information

d modelling patient interactions

e restricting case teaching to narrow concepts. 